\title{
FATIGUE LIFE EVALUATION OF SUSPENSION KNUCKLE USING MULTIBODY SIMULATION TECHNIQUE
}

\author{
M. Kamal ${ }^{1}$, M.M. Rahman ${ }^{1,2}$ and A.G.A. $\operatorname{Rahman}^{1}$ \\ ${ }^{1}$ Faculty of Mechanical Engineering \\ ${ }^{2}$ Automotive Engineering Centre \\ Universiti Malaysia Pahang, 26600 Pekan, Pahang Malaysia \\ Email: mustafizur@ump.edu.my
}

\begin{abstract}
Suspension is part of automotive systems, providing both vehicle control and passenger comfort. The knuckle is an important part within the suspension system, constantly encountering the cyclic loads subjecting it to fatigue failure. This paper presents an evaluation of the fatigue characteristics of a knuckle using multibody simulation (MBS) techniques. Load time history extracted from the MBS is used for stress analysis. An actual road profile of road bumps was used as the input to MBS. The stress fluctuations for fatigue simulations are considered with the road profile. The strain-life method is utilized to assess the fatigue life. The instantaneous stress distributions and maximum principal stress are used for fatigue life predictions. Mesh sensitivity analysis has been performed. The results show that the steering link in the knuckle is found to be the most susceptible region for fatigue failure. The number of times the knuckle can manage a road bump at $40 \mathrm{~km} / \mathrm{hr}$ is determined to be approximately 371 times with a $50 \%$ certainty of survival. The proposed method of using the loading time history extracted from MBS simulation for fatigue life estimation is found to be very promising for the accurate evaluation of the performance of suspension system components.
\end{abstract}

Keywords: Fatigue, multibody simulation, suspension system, knuckle, strain-life method, maximum principal stress.

\section{INTRODUCTION}

Suspension systems support the weight of the car and make it possible for the vehicle to travel on irregular surfaces with the minimum disturbance transferred to the passengers. It also allows the vehicle to corner with minimal rolling and to maintain the traction between the tires and road, thus providing control and safety. It consists of a knuckle, spring, shock absorber and control arms (Liu, 2008; Kamal \& Rahman, 2012). The knuckle is an important member of the suspension system, and its integrity assessment is significant with respect to safe design life prediction. The knuckle constantly faces time-varying loads during its service life. There are various points of application of structural loads to be applied in different directions at the same time, resulting in complex stress and strain fields (Azrulhisham, Asri, Dzuraidahm, Nik Abdullah, Shahrum, \& Che Hassan, 2010). Due to these variable loads it is essential to predict the safe design life of the component in real-world loading conditions (Zoroufi \& Fatemi, 2006; Rahman, Ariffin, Abdullah, Noor, Bakar, \& Maleque, 2008a; Rahman, Ariffin, Jamaludin, Abdullah, \& Noor, 2008b; Rahman, Ariffin, Rejab, Kadirgama, \& Noor 2009a; Rahman, Ariffin, Abdullah, Noor, \& Bakar, 2009b). Fatigue simulations rely on the stress/strain distribution in the component under consideration to correctly predict the fatigue life (Fatemi \& Shamsaei, 2011; Rahman, Ariffin, Jamaludin, \& Haron, 2005, 
2006, 2007; Rahman, Kadirgama, Noor, Rejab, \& Kesulai, 2009c). Thus it is necessary to apply the loads in three dimensions, making it close to the loads the part faces in the real-world situation. A multi body simulation is required to calculate the load time history at the points where the knuckle is connected to the suspension system (Kang, Park, Heo, Ryu, \& Jeong, 2010). In this paper, the evaluation of the fatigue life of a suspension knuckle using the multi body simulation technique is presented.

\section{METHODOLOGY}

A methodology is developed to use the load time history for fatigue life prediction when a road bump profile is considered as the input loading. Linear elastic analysis is performed using ANSYS software where the loads are the forces calculated from MBS. The ncode Designlife software is used for fatigue life estimation. The suspension of a Proton SAGA is used in this study, and the material of the knuckle considered is FCD500-7 (Azrulhisham et al, 2010). Fatigue properties for the fatigue life simulations are taken from ASTM A-536, which is equivalent to FCD500-7 (GMI, 2012; MP, 2012).

\section{Multi Body Simulation}

Multi body simulations are carried out to study of the kinetic/kinematic behavior of mechanisms. The motion and forces required, and the forces, moments, accelerations and position of each component of the assembly can be calculated and monitored in three dimensions. The components of assemblies are considered as rigid bodies, so their shape is not changed due to the application of forces during the simulations. For deformation and stresses produced in the components due to dynamic loads, a separate FE simulation is required; for which the instantaneous loads can be extracted from the MBS results (Miao, Zhang, Zhang \& Jin, 2009).

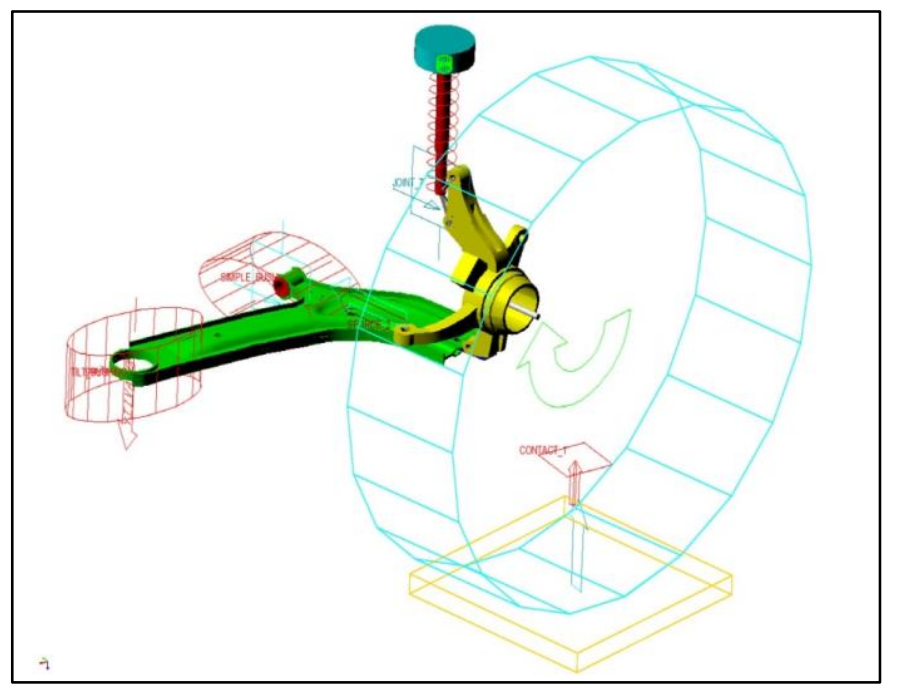

Figure 1. MBS model for Mac Phearson Strut type suspension

In the present study the Mac Phearson strut type suspension system of a Proton Saga was used. The spring damper, knuckle and lower suspension arm have been modeled using the quarter car modeling approach as shown in Figure 1. The models for the knuckle and lower suspension arm were developed from real parts, and the weight 
and diameter of the tire was determined from an actual Proton Saga tire. The tire's flexibility can be ignored and is modeled as a rigid tire, as the road profile of the road bumps at $40 \mathrm{Km} / \mathrm{hr}$, presented in Figure 2, was acquired using a test car and the effect of tire flexibility is included in the profile data.

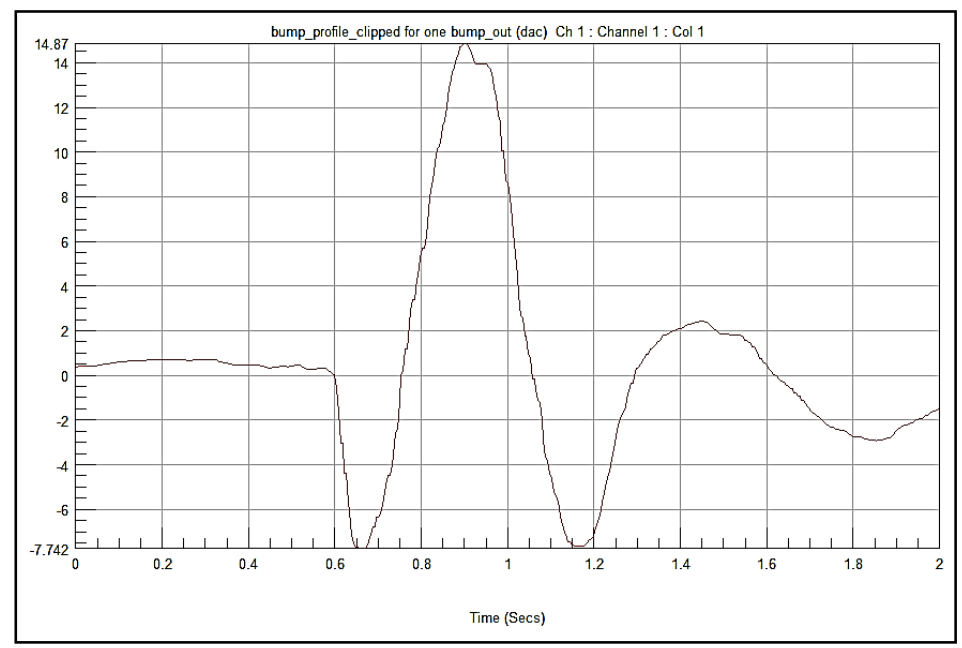

Figure 2. Road bump profile at $40 \mathrm{~km} / \mathrm{hr}$ (tire deflection versus time)

\section{Finite Element Analysis}

The knuckle is modeled as a linear structural analysis component. Loads are applied on the component at the locations shown in Figure 3. The value of instantaneous loads are determined from the MBS results, where the road bumps profile was used as the input and applied in the structural analysis as separate load steps. The instant where the maximum value of stress occurs is identified by running a stress analysis over the load time history extracted from the MBS results. This instantaneous stress distribution was used to predict fatigue life. An unstructured meshing scheme was used for mesh generation using a Tetrahedral with 10 -node elements, as they can very accurately capture the typical geometry topology in a FEM model, which is shown in Figure 4.

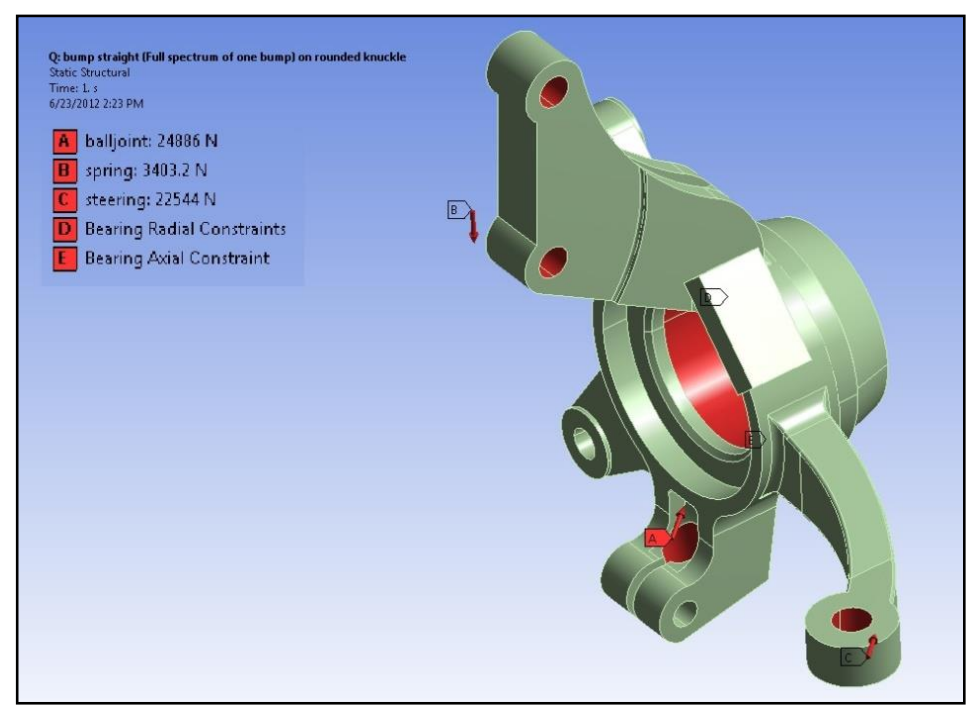

Figure 3. Location of applied loads and constraints 


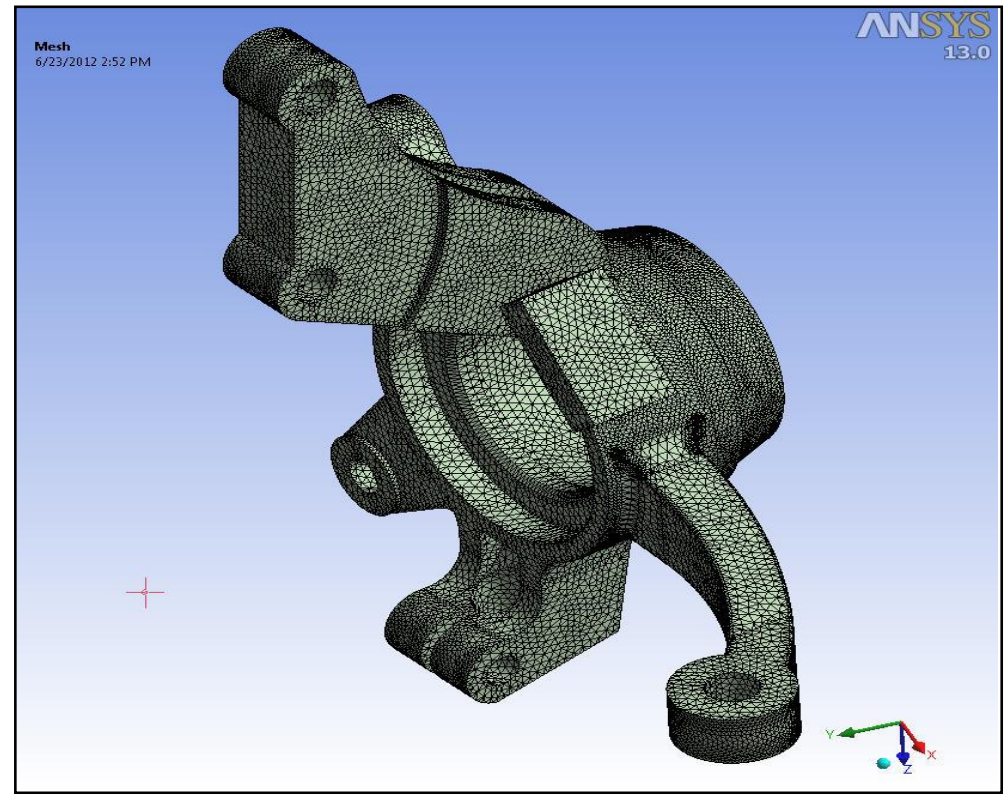

Figure 4. Unstructured mesh of knuckle using Tet10 elements

\section{Mesh Sensitivity Analysis}

Mesh sensitivity analysis was performed to obtain the mesh size, which has reasonable accuracy and solution time. The convergence of the mesh is based on the model, geometry, topology and analysis objectives. For the analysis, an unstructured tetrahedral meshing scheme was used with Tet10 elements as they are of higher order and accurately capture the curved surfaces. The loading conditions and FEM model are shown in Figures 3 and 4. The convergence of stress is selected as the main criteria for mesh size selection. The location with the maximum value of maximum principal stress is monitored for mesh convergence. Table 1 shows the variation in stresses with the change in global mesh size. It can be seen that the stress results show convergence at a mesh size of $1.15 \mathrm{~mm}$, however Figure 6 shows that the number of nodes and elements will place an excess load on the CPU and storage capacity. It can be seen that there is a sharp increase in the number of nodes after a $1.25 \mathrm{~mm}$ mesh size. It is concluded that the appropriate mesh size of $1.25 \mathrm{~mm}$ is to be selected as it produces an acceptable FEM model size and solution time with reasonable accuracy.

Table 1. Variation in stresses with change in global mesh size.

\begin{tabular}{|c|c|c|c|c|c|}
\hline \multirow[b]{2}{*}{$\begin{array}{c}\text { Global } \\
\text { mesh size } \\
(\mathrm{mm})\end{array}$} & \multirow[b]{2}{*}{ Total nodes } & \multirow[b]{2}{*}{$\begin{array}{c}\text { Total } \\
\text { elements }\end{array}$} & \multicolumn{3}{|c|}{ Stress } \\
\hline & & & $\begin{array}{c}\text { Von Mises } \\
(\mathrm{MPa})\end{array}$ & $\begin{array}{l}\text { Tresca } \\
(\mathrm{MPa})\end{array}$ & $\begin{array}{c}\text { Max. } \\
\text { Principal } \\
(\mathrm{MPa})\end{array}$ \\
\hline 2.25 & 112579 & 65378 & 638 & 654 & 655 \\
\hline 2 & 134040 & 77939 & 641 & 658 & 660 \\
\hline 1.75 & 170374 & 99446 & 645 & 662 & 665 \\
\hline 1.5 & 221905 & 130323 & 651 & 668 & 670 \\
\hline 1.25 & 303842 & 179316 & 655 & 671 & 673 \\
\hline 1.15 & 362442 & 215675 & 656 & 672 & 674 \\
\hline
\end{tabular}




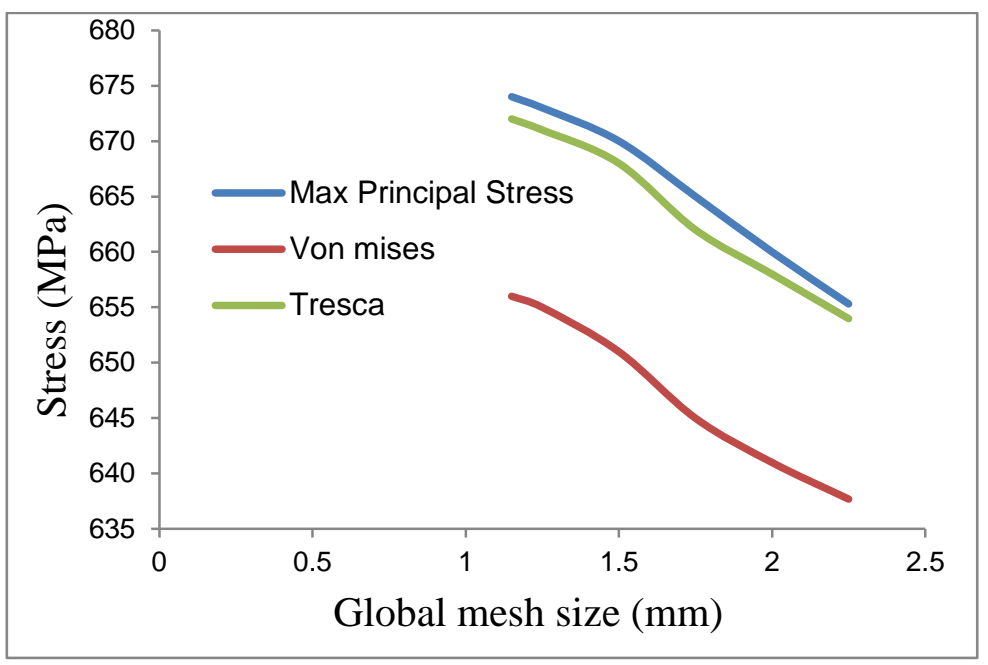

Figure 5. Mesh size versus stress results

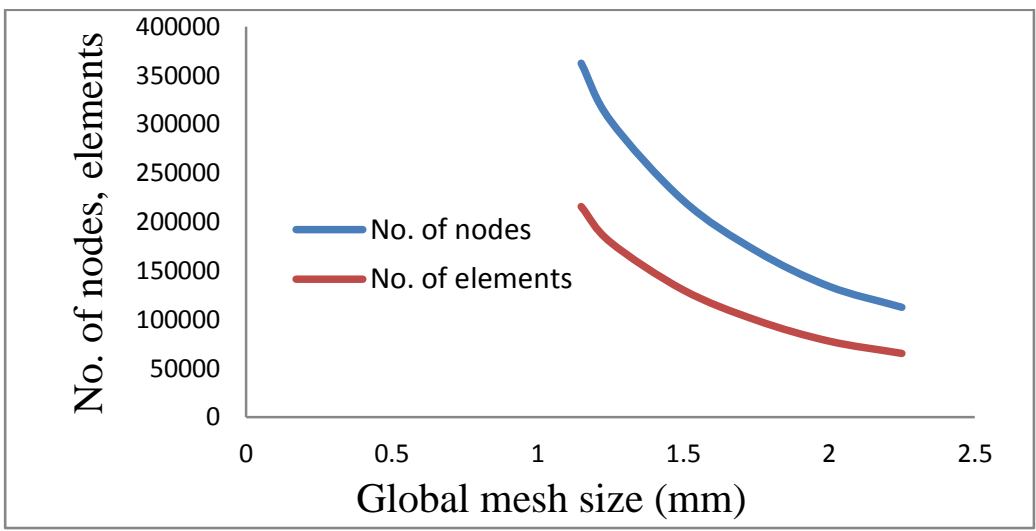

Figure 6. Mesh size versus number of nodes and elements

\section{FATIGUE ANALYSIS}

Three approaches, including the stress-life, strain-life, and crack-growth methodologies, are used for fatigue analysis. The stress-life $(S-N)$ method in which a relationship between the nominal elastic stress is used to estimate fatigue life. This method gives reasonably accurate results for components where only elastic stresses and strains are present (Bannantine, Comer, \& Handrock, 1989). As for these conditions, the strain-life $(E-N)$ method uses the local strains as the governing fatigue parameter. The local strainlife approach is selected when the loading history is random and where the mean stress and the load sequence have a significant effect. The strain-life approach involves techniques for converting the loading history, geometry and material properties (monotonic and cyclic) input into a fatigue life prediction (Stephens, Fatemi, Stephens, $\&$ Fuchs, 2001). The prediction process involves sequential operations, as shown in Figure 7. The first step is to estimate the critical region stress and strain distribution and then the rainflow cycle counting method (Matsuishi \& Endo, 1968) is used to reduce the load-time history. The next step is to use the finite element method to convert the reduced load-time history into a strain-time history, and also to calculate the stress and strain in the highly stressed area. Crack initiation methods are employed to predict the 
fatigue life. The simple linear hypothesis is proposed (Palmgren, 1924), and it is used to determine the fatigue damage (Miner, 1945). Finally, the damage values for all cycles are summed until a critical damage sum (failure criteria) is reached.

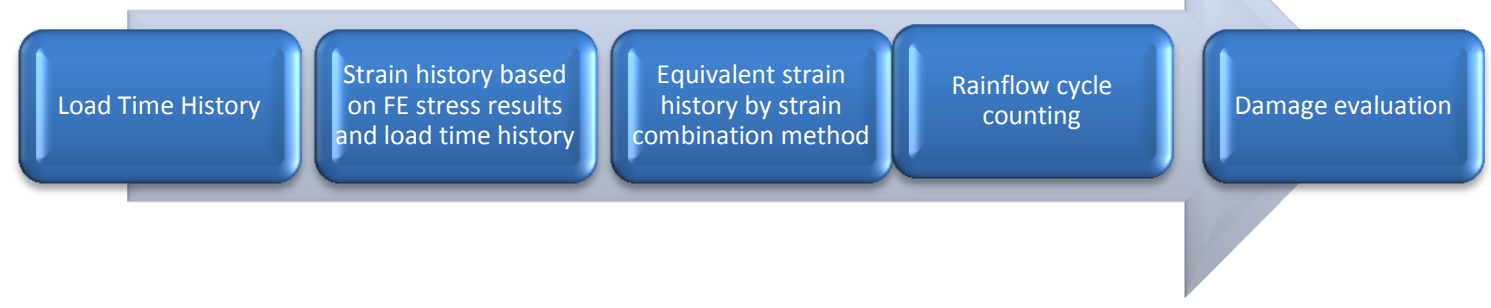

Figure 7. Strain-life analysis steps.

The strain-life method is utilized to estimate fatigue damage. The strain-life curve is used to characterize the fatigue resistance of metals. The relationship between the total strain amplitude $\left(\varepsilon_{a}\right)$ and reversals to failure $\left(2 N_{f}\right)$ can be mathematically expressed as in Eq. (1) (Lee, Pan, Hathaway \& Barkey, 2005).

$$
\varepsilon_{a}=\frac{\sigma_{f}^{\prime}}{E}\left(2 N_{f}\right)^{b}+\varepsilon_{f}^{\prime}\left(2 N_{f}\right)^{c}
$$

where, $N_{f}$ is the fatigue life; $\sigma_{f}^{\prime}$ is the fatigue strength coefficient; $E$ is the modulus of elasticity; $b$ is the fatigue strength exponent; $\varepsilon_{f}$ is the fatigue ductility coefficient, and $c$ is the fatigue ductility exponent.

The absolute maximum principal strain method is used to combine component strains, see Eq. (2).

$$
\varepsilon_{A M P}=\varepsilon_{3} \text { if }\left|\varepsilon_{3}\right|>\left|\varepsilon_{1}\right| \text { otherwise } \varepsilon_{A M P}=\varepsilon_{1}
$$

where, $\varepsilon_{A M P}$ is an absolute maximum principal strain, and $\varepsilon_{1}$ and $\varepsilon_{3}$ are the first and third principal strains.

Morrow's model is used for mean stress $\left(\sigma_{m}\right)$ corrections in Eq. (3).

$$
\varepsilon_{a}=\frac{\left(\sigma_{f}^{\prime}-\sigma_{m}\right)}{E}\left(2 N_{f}\right)^{b}+\varepsilon_{f}^{\prime}\left(2 N_{f}\right)^{c}
$$

The Hoffman-Seeger model (Hoffman \& Seeger, 1989) is used for elastic-plastic corrections. The cyclic material properties are used to calculate the elastic-plastic stressstrain response and the rate at which fatigue damage accumulates due to each fatigue cycle.

\section{Materials Information}

The required material parameters depend on the analysis methodology being used. The material model considered material as being elastic and isotropic. The knuckle is verified for fatigue life using n-code Design-life. It is made with FCD500-7 (equivalent 
alloy ASTM A-536). The mechanical properties of FCD500-7 and its fatigue strain-life properties are listed in Table 2.

Table 2. Mechanical and cyclic properties of FCD500-7 and ASTM A536 (Liu, 2008)

\begin{tabular}{lc}
\hline \multicolumn{1}{c}{ Parameter, unit } & Value \\
\hline Young's Modulus $(E), \mathrm{GPa}$ & 170 \\
Yield strength $\left(\sigma_{y}\right), \mathrm{MPa}$ & 360 \\
Ultimate strength $\left(\sigma_{u}\right), \mathrm{MPa}$ & 520 \\
Density $\left(\mathrm{Kg} / \mathrm{m}^{3}\right)$ & 7140 \\
Work hardening exponent $(n)$ & 0.18 \\
Work hardening coefficient $(K), \mathrm{MPa}$ & 659 \\
Fatigue strength coefficient $\left(S_{f}^{\prime}\right), \mathrm{MPa}$ & 585 \\
Fatigue strength exponent $(b)$ & -0.075 \\
Fatigue ductility exponent $(c)$ & -0.751 \\
Fatigue ductility coefficient $\left(E_{f}^{\prime}\right)$ & 0.666 \\
Cyclic strain hardening exponent $\left(n{ }^{\prime}\right)$ & 0.14 \\
Cyclic strength coefficient $\left(K^{\prime}\right), \mathrm{MPa}$ & 877 \\
\hline
\end{tabular}

\section{RESULTS AND DISCUSSION}

Multi body simulation was performed using MSC.ADAMS to extract the forces on the mounting points of a knuckle in a suspension system. The linear stress analysis was performed utilizing ANSYS software to determine the stress and strain results from the finite-element model, with forces from MBS results applied as the loads. The maximum principal stress contour is shown in Figure 8. It can be observed that a maximum principal stress of $672 \mathrm{MPa}$ occurs at the steering link. The von Mises and Tresca stress at this location were found to be 651 and $668 \mathrm{MPa}$. The von Mises and Tresca stress contours are shown in Figure 9. It is important to note that the values of maximum stress for all the three stress results are greater than the UTS of the material. This shows that plastic deformation is induced during the application of the loads. This point is important as it is necessary to include an elastic-plastic correction method to the stress values when evaluating the fatigue life.

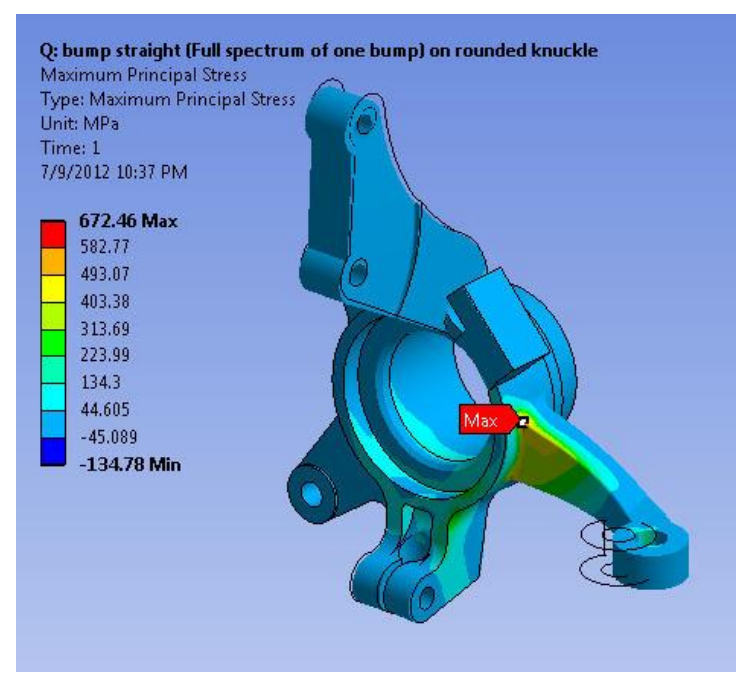

Figure 8. Maximum principal stress contours 
The road bumps profile at $40 \mathrm{~km} / \mathrm{hr}$ is considered as the input (Figure 2). The strain-life method is used for fatigue life prediction, and an absolute maximum principal strain method is used to combine the strain history. For elastic-plastic correction, the Hoffman-Seegar method is used. The certainty of survival is set as $50 \%$, which is a safe approximation in most cases. The fatigue life contour is shown in Figure 10. The fatigue life of the knuckle is determined as approximately 371 times, when facing the road bump at $40 \mathrm{~km} / \mathrm{hr}$. According to the European Commission's road safety recommendations (EC, 2012), $30 \mathrm{~km} / \mathrm{hr}$ is the speed limit in residential zones in which road bumps are used to reduce/control vehicle speed. The case of crossing a road bump at $40 \mathrm{~km} / \mathrm{hr}$ rarely occurs, however a $40 \mathrm{~km} / \mathrm{hr}$ speed for profile data acquisition was selected to obtain conservative results. It is concluded that a fatigue life of 371 times of facing a road bump at $40 \mathrm{~km} / \mathrm{hr}$ is sufficient to declare the knuckle under study safe according to this type of load case.

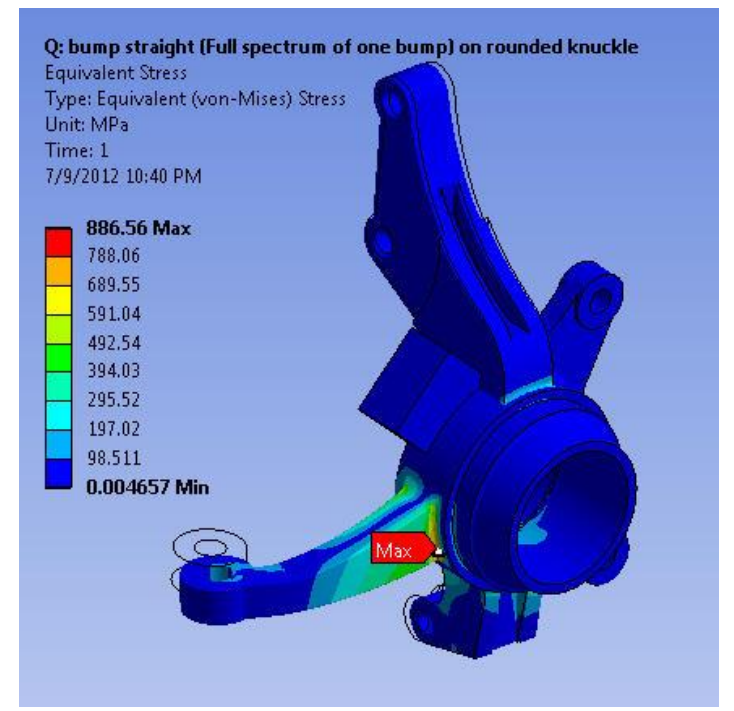

(a) von Mises stress

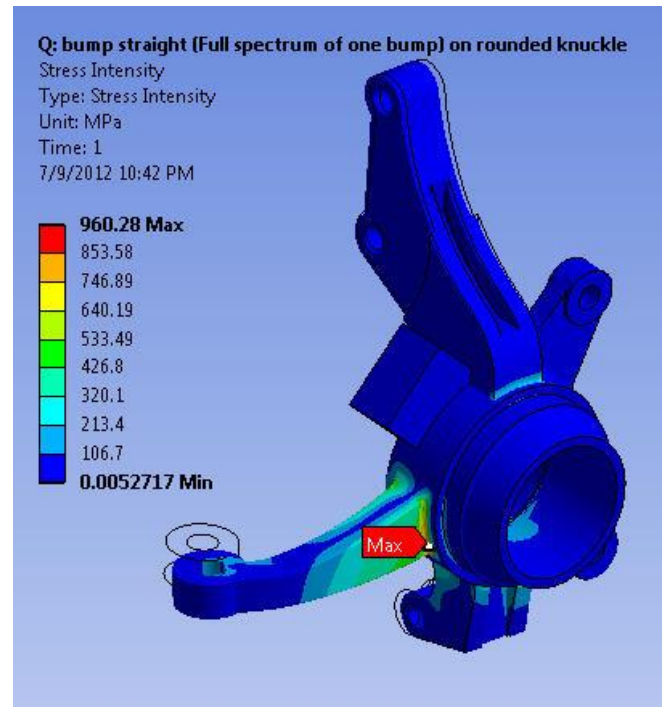

(b) Tresca stress

Figure 9. Stress contours for different methods

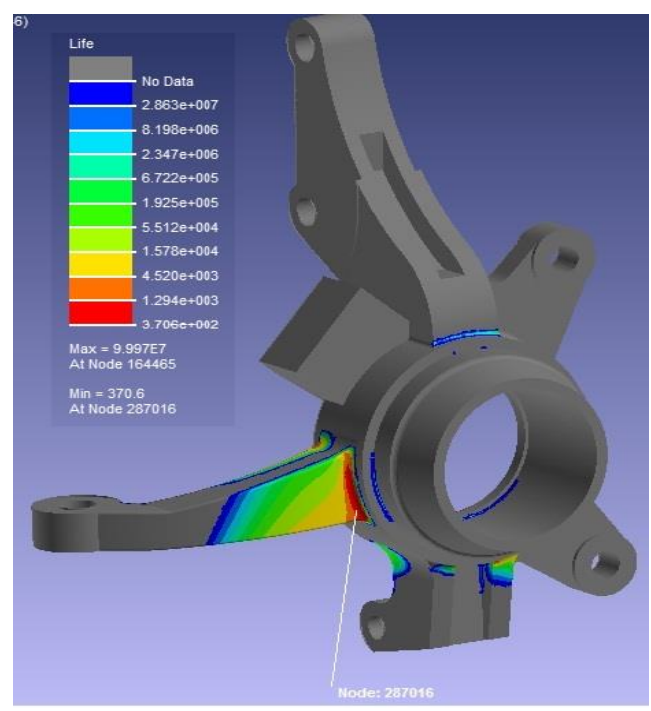

Figure 10. Fatigue life in repetitions of load time history. 


\section{CONCLUSION}

An automotive suspension system knuckle is analyzed for fatigue failure. Multi body simulation (MBS) is performed to generate the load time history on the knuckle from an actual road bump profile. The linear stress analysis for every instance of extracted force is performed, and the load instance causing the maximum stress is selected and used for fatigue life prediction. The steering link is found to be the most susceptible region for fatigue failure. The number of times the knuckle can face a road bump at $40 \mathrm{~km} / \mathrm{hr}$ with a $50 \%$ certainty of survival is approximately 371 , prior to crack initiation at the steering link. This type of driving condition very rarely occurs during the car's life time, as the recommended speed for areas in which road bumps are used to control speeds is 30 $\mathrm{km} / \mathrm{hr}$. Thus the knuckle can be declared as being safe for this kind of loading condition. The study shows that the application of MBS to extract loads for fatigue analysis is a unique and reliable technique to obtain realistic stress distributions, which makes it easy to, and increases confidence in, selecting the damaging stress cases for fatigue life estimation.

\section{REFERENCES}

Azrulhisham, E. A., Asri, Y. M., Dzuraidahm, A. W., Nik Abdullah, N. M., Shahrum, A., \& Che Hassan, C. H. (2010). Evaluation of fatigue life reliability of steering knuckle using Pearson parametric distribution model. International Journal of Quality, Statistics, and Reliability, 1-8.

Bannantine, J. A., Comer, J. J., \& Handrock, J. L. (1989). Fundamentals of metal fatigue analysis. New York, Prentice Hall.

EC (European Commission) (2012). Retrieved from http://ec.europa.eu/ transport/ road_safety/specialist/knowledge/pedestrians/measures_tt_reduce_crash_numbe rs_and_injury_severity/road_design.htm [Accessed 7th July 2012].

Fatemi, A., \& Shamsaei, N. (2011). Multiaxial fatigue: an overview and some approximation models for life estimation. International Journal of Fatigue, 33, 948-958.

GMI (Granta Material Intelligence) (2012). Retrieved from http:// www.grantadesign. com/resources/materials/designations/ferrous.generalcastiron.htm [Accessed 16th June 2012].

Hoffman, M., \& Seeger, T. (1989). Estimating multiaxial elastic-plastic notch stresses and strains in combined loading. In: Brown, M. W. and Miller, K. J. (eds.) Biaxial and multiaxial fatigue. EGF3. London, Mechanical Engineering Publications, pp. 3-24.

Kamal, M., \& Rahman, M. M. (2012). Study on the dynamic behavior of wishbone suspension system. IOP Conference Series: Materials Science and Engineering, 36(012019), 1-8.

Kang, D. O., Park, K., Heo, S. J., Ryu, Y., \& Jeong, J. (2010). Development and application of VPG simulation technique based on equivalent virtual road profile. International Journal of Precision Engineering and Manufacturing, 11(2), 265-272.

Lee, Y. L., Pan, J., Hathaway, R. B., \& Barkey, M. E. (2005). Fatigue testing and analysis, theory and practice. Burlington, Elsevier Butterworth-Heinemann.

Liu, Y. (2008). Recent innovations in vehicle suspension systems. Recent Patents on Mechanical Engineering, 1, 206-210. 
Matsuishi, M., \& Endo, T. (1968). Fatigue of metals subjected to varying stress. Fukuoko, Japan, Japan Society of Mechanical Engineers.

Miao, B., Zhang, W., Zhang, J. \& Jin, D. (2009). Evaluation of railway vehicle car body fatigue life and durability using multidisciplinary analysis method. International Journal of Vehicle Structures and Systems, 1(4), 85-92.

Miner, A. (1945). Cumulative damage in fatigue. Journal of Applied Mechanics, 12, 159-164.

MP (Magic Precision Inc.) (2012). Retrived from: http://www.gprecision.com/ resources/cast-iron-standards.html [Accessed 20th May 2012].

Palmgren, A. (1924). Durability of ball bearings. ZVDI, 68 (14), 339-341.

Rahman, M. M., Ariffin, A. K., Jamaludin, N., \& Haron, C. H. C. (2005). Vibration fatigue analysis of cylinder head of a new two-stroke free piston engine using finite element approach. Structural Integrity and Durability, 1(2), 121-129.

Rahman, M. M., Ariffin, A. K., Jamaludin, N., \& Haron, C. H. C. (2006). Influence of surface treatments on fatigue life of a free piston linear generator engine component using Random Loading. Journal of Zhejiang University of Science Part A, 7(11), 1819-1830

Rahman, M. M., Ariffin, A. K., Jamaludin, N., \& Haron, C. H. C. (2007). Finite element based durability assessment of a free piston linear engine component. Journal of Structural Durability and Health Monitoring, 3(1), 1-13.

Rahman, M. M., Ariffin, A. K., Abdullah, S., Noor, M. M., Bakar, R. A., \& Maleque, M. A. (2008a). Finite element based fatigue life prediction of cylinder head for two-stroke linear engine using stress-life approach. Journal of Applied Sciences, 8(19), 3316-3327.

Rahman, M. M., Ariffin, A. K., Jamaludin, N., Abdullah, S., \& Noor, M. M. (2008b). Finite element based fatigue life prediction of a new free piston engine mounting. Journal of Applied Sciences, 8(9), 1612-1621.

Rahman, M. M., Ariffin, A. K., Jamaludin, N., Haron, C. H. C., \& Bakar, R. A. (2008c). Fatigue life prediction of two-stroke free piston engine mounting using frequency response approach. European Journal of Scientific Research, 22(4), 480-493

Rahman, M. M., Ariffin, A. K., Rejab, M. R. M., Kadirgama, K., \& Noor, M. M. (2009a). Multiaxial fatigue behaviour of cylinder head for a free piston linear engine. Journal of Applied Sciences, 9(15), 2725-2734.

Rahman, M. M., Ariffin, A. K., Abdullah, S., Noor, M. M., \& Bakar, R. A. (2009b). Durability assessment of cylinder block for two stroke free piston linear engine using random loading. American Journal of Applied Sciences, 6(4), 726-735.

Rahman, M. M., Kadirgama, K., Noor, M. M., Rejab, M. R. M., \& Kesulai, S. A. (2009c). Fatigue life prediction of lower suspension arm using strain-life approach. European Journal of Scientific Research, 30(3), 437-450.

Stephens, R. I., Fatemi, A., Stephens, R. R., \& Fuchs, H. O. (2001). Metal fatigue in Engineering. 2nd ed. New York, John Wiley and Sons.

Zoroufi, M., \& Fatemi, A. 2006. Experimental durability assessment and life prediction of vehicle suspension components: a case study of steering knuckles. Proceedings of the Institution of Mechanical Engineers Part D, 220(11), 15651579. 